\section{Patrícia Moreira Rabello'}

Arnaldo de França Caldas Júnior"I

\title{
Violência contra a mulher, coesão familiar e drogas
}

\section{Violence against women, family cohesion and drugs}

\section{RESUMO}

OBJETIVO: Avaliar a associação entre coesão, adaptabilidade e risco mental familiar com violência física contra a mulher e uso de drogas.

MÉTODOS: Estudo tipo caso-controle pareado realizado entre 2004 e 2005 na cidade de João Pessoa, Paraíba. A amostra foi constituída por 260 mulheres, divididas em 130 agredidas e 130 não agredidas. $O$ grupo caso foi constituído de mulheres que prestaram queixa por agressão física doméstica na Delegacia Especializada da Mulher. O grupo controle foi pareado com mulheres vizinhas de bairro das vítimas queixosas na Delegacia. A coesão, a adaptabilidade e o risco mental foram avaliados pela escala Family Adaptability and Cohesion Evaluation Scales. Na análise estatística, foram utilizados os testes qui-quadrado e Exato de Fisher, com nível de significância de 5\%.

RESULTADOS: Os dois grupos se comportaram de forma diferente em relação ao risco mental e coesão, mas semelhantes quanto à adaptabilidade familiar $(p=0,0917)$. As mulheres agredidas apresentaram risco mental alto $(43,1 \%) \mathrm{e}$ médio $(39,2 \%)$, diferentemente das não agredidas $(\mathrm{p}=0,0016)$, que apresentaram médio risco $(55,4 \%)$. Houve diferença significativa entre os dois grupos para o uso de drogas, com consumo maior nas famílias das mulheres agredidas $(90,8 \%)$ do que das não agredidas (56,9\%). A droga mais utilizada foi o álcool, sendo o mais alto fator de risco para a agressão, quando consumido diariamente $(\mathrm{OR}=37,33)$ ou associado a outra droga $(\mathrm{OR}=29,56)$.

CONCLUSÕES: O desequilíbrio pela falta de união entre a família e o uso de drogas altera decisivamente no funcionamento familiar, podendo gerar conflitos e agressões domésticas.

DESCRITORES: Violência contra a mulher. Transtornos relacionados ao uso de substâncias. Saúde mental. Estudos de casos e controles.

Departamento de Clínica e Odontologia Social. Universidade Federal da Paraíba. João Pessoa, PB, Brasil

I Faculdade de Odontologia da Universidade de Pernambuco. Camaragibe, PE, Brasil

Correspondência | Correspondence: Patrícia Moreira Rabello

Campus I

Departamento de Clínica e Odontologia Social Cidade Universitária

58051-900 João Pessoa, PB, Brasil

E-mail: patriciamrabello@ig.com.br 


\begin{abstract}
OBJECTIVE: To evaluate the association between cohesion, adaptability and mental risk in families, physical violence against women and the use of drugs.

METHODS: Data for this paired case-control study was collected in 2004 and 2005 in the city of Joao Pessoa, in Northeastern Brazil. The sample included 260 women, divided into 130 battered individuals and 130 non-battered. The case study group consisted of women who lodged complaints for domestic violence at the Specialist Women's Police Station. The control group was made up of women living in the same neighborhood as those who had made the complaint. Cohesion, adaptability and mental risk were all measured using the "Family Adaptability and Cohesion Evaluation Scales". For the statistical analysis the Chi-square and the Fisher's Exact Tests ere used, at a significance level of $5 \%$.
\end{abstract}

RESULTS: The two groups differed for measures relating to mental risk and cohesion, but had similar results for family adaptability $(\mathrm{p}=0.0917)$. The women victims of domestic violence had high $(43.1 \%)$ and medium $(39.2 \%)$ mental risk, while the non-victims had only medium risk (55.4\%). There was a significant difference in drug use between the two groups, with greater consumption among the families of battered women (90.8\%) compared with those of non-battered women (56.9\%). The most widely used drug was alcohol, which also represented the highest risk factor for aggression if consumed daily $(\mathrm{OR}=37.33)$ or in conjunction with other drugs $(\mathrm{OR}=29,56)$.

CONCLUSIONS: Both the instability caused by a lack of family unity and the use of drugs significantly affect family functioning and may give rise to conflict and domestic violence.

KEY WORDS: Violence against women. Substance-related disorders. Mental health. Case-control studies.

\section{INTRODUÇÃO}

A literatura relata a associação entre violência nas relações de gênero e maior ocorrência de diversos problemas de saúde. ${ }^{22} \mathrm{~A}$ violência de gênero é considerada um problema de saúde pública, com repercussões físicas e mentais nas mulheres. ${ }^{23}$ Entretanto, muitas vezes essa violência não chega a ser investigada pelo profissional da saúde, sendo subestimada nas estatísticas oficiais quanto à freqüência e efeitos na sociedade. Segundo Penna et $\mathrm{al}^{20}$ (2004), é recente a projeção do tema violência doméstica como fenômeno social no mundo acadêmico.

Muitas pesquisas mostram que é no espaço doméstico onde acontece a maior parte das agressões à mulher, ${ }^{1,9,12}$ legitimadas por uma ordem patriarcal de organização familiar, onde a dominação masculina é vista como natural.

Atualmente, o ritmo acelerado da vida e a fragmentação das relações afetivas levaram a família a uma nova dinâmica e, conseqüentemente, a mudanças de padrão [de convivência?]. Com a entrada da mulher no mercado de trabalho, as famílias diminuíram o número de filhos e a mulher acumulou as funções externas ao trabalho doméstico, aumentando o estresse e alterando o equilíbrio interno das famílias. ${ }^{3,6,8,13,19}$

O equilíbrio de uma família também é alterado quando um dos membros consome drogas, lícitas ou ilícitas. Vários trabalhos associam o alto consumo do álcool à desagregação familiar. ${ }^{15,22}$ Essa substância é consumida em larga escala no Brasil, principalmente por homens, levando-os a mudanças de humor que repercutem desfavoravelmente na mulher, submetendo-as à violência física.

O objetivo do presente estudo foi avaliar os fatores associados à agressão física contra a mulher e o uso de drogas entre os envolvidos na situação de violência.

\section{MÉTODOS}

Estudo caso-controle, pareado por local de residência, idade e número de filhos, realizado no município de João Pessoa, estado da Paraíba, com 660.797 habitantes, 
dos quais 351.941 são mulheres.* $\mathrm{O}$ desenho de estudo foi escolhido para comparar se os casos diferiam significativamente dos controles em relação à exposição aos fatores de risco para a violência física contra a mulher.

O critério de inclusão de casos foi ser mulher e ter sofrido lesões corporais físicas provocadas por alguém da família. Agressões físicas praticadas por estranhos, vizinhos, ou violências psíquicas e sexuais foram excluídas do grupo caso. O grupo caso foi constituído por 130 mulheres que prestaram queixa de agressão física na Delegacia Especializada da Mulher, em 2004 e 2005 .

O grupo controle foi composto por 130 mulheres vizinhas de bairro dos casos. O critério de inclusão foi nunca ter sofrido agressão pela família e, portanto, nunca ter prestado queixa contra a família na delegacia. Ao total, 260 mulheres foram analisadas.

Os cálculos da amostra foram obtidos por meio de estudo piloto constituído por 60 mulheres, divididas em dois grupos (30 casos e 30 controles), não incluídos no estudo principal. O tamanho da amostra foi determinado levando-se em consideração os valores do odds ratio (OR) de 3,27, uma exposição no grupo controle esperada de $20 \%$, margem de erro $(\alpha)$ de $1 \%$ e poder do teste de $95 \%$ (erro $\beta$ ), calculados no programa EpiInfo.

As mulheres selecionadas foram entrevistadas utilizando-se questionário especificamente elaborado para a finalidade da pesquisa. Inicialmente, a coleta de dados foi realizada com os casos na delegacia e depois as entrevistadas foram pareadas com as suas vizinhas. $\mathrm{O}$ questionário foi aplicado por apenas um pesquisador, calibrado e treinado no estudo piloto. Esse questionário foi dividido em duas partes. A primeira abordava as informações referentes às variáveis socioeconômicas e demográficas (idade, anos de estudo, renda mensal familiar, classe econômica, número de filhos, número de pessoas que moravam na casa), parentesco do agressor e freqüência e tipo de droga consumida pelo membro da família. A classe socioeconômica das mulheres foi verificada de acordo com os critérios da Associação Brasileira de Institutos de Pesquisa de Mercado (ABIPEME). ${ }^{14}$

$\mathrm{Na}$ segunda parte do questionário, o funcionamento familiar foi avaliado utilizando-se a escala diagnóstica Family Adaptability and Cohesion Evaluation Scales (FACES III), criada por Olson et al ${ }^{21}$ (1989) e validada no Brasil por Falceto et $\mathrm{al}^{8}$ (2000). Esse instrumento avalia o risco mental, a coesão e a adaptabilidade familiar. A escala FACES III é composta por 20 perguntas. As dez questões de número ímpar avaliam a coesão familiar, definida como a capacidade de a família manter-se unida frente às vicissitudes do cotidiano. As demais perguntas referem-se à adaptabilidade, ou seja, a capacidade de os membros da família modificarem papéis e regras de funcionamento para adequá-los às tarefas ou a um momento a enfrentar. A partir das perguntas sobre coesão e adaptabilidade, o instrumento FACES III fornece o risco mental familiar. De acordo com esse modelo, as famílias equilibradas possuem níveis médios de coesão e adaptabilidade, enquanto as famílias clínicas tendem a ter valores extremos. Olson et a ${ }^{18}$ (1989) classificaram as famílias em três grupos, utilizando a combinação das características de coesão e adaptabilidade: 1) famílias balanceadas - que correspondem a famílias de baixo risco mental, 2) famílias de risco mental médio e 3) famílias de alto risco mental $\mathrm{Na}$ análise estatística, utilizaram-se os programas SPPS 11 e SAS 8. A margem de erro adotada na decisão dos testes estatísticos foi de 5\%. Para algumas variáveis, foram utilizadas as medidas de tendência central e de dispersão (média e desvio-padrão).

Os testes qui-quadrado $\left(\chi^{2}\right)$ e Exato de Fisher, incluindo OR, foram realizados para avaliar a relação entre as variáveis agrupadas duas a duas, sendo a variável dependente relacionada a cada uma das variáveis independentes. A regressão logística foi aplicada para avaliar associação entre uso de drogas, risco mental, coesão e adaptabilidade familiar.

O modelo de regressão foi ajustado considerando-se dois modelos de variáveis independentes: o primeiro para uso de droga e risco mental e o segundo para uso de droga, coesão e adaptabilidade familiar. A justificativa para o ajuste dos dois modelos foi a elevada correlação entre risco mental com coesão e adaptabilidade. A não inclusão das variáveis freqüência de uso da droga, tipo da droga e quais membros da família utilizam a droga, foi devido à alta correlação com a variável uso da droga. A junção das categorias família conectada e aglutinada na variável coesão familiar foi devido à ocorrência de freqüência nula, assim, a junção se fez necessária para possibilitar o cálculo do OR. Nesse modelo, foram incluídas somente as variáveis que apresentaram significância $(\mathrm{p} \leq 0,20)$ na análise bivariada.

A pesquisa obedeceu às normas da Resolução 196/96 que regulamenta pesquisas com seres humanos e foi aprovada no Comitê de Ética em Pesquisa (CEP), da Universidade Federal da Paraíba.

\section{RESULTADOS}

A idade média das 260 mulheres analisadas foi de 30,64 anos ( $\mathrm{DP}=9,82)$, sem diferença estatisticamente

* Instituto Brasileiro de Geografia e Estatística. Censo demográfico 2000: Características da população e dos domicílios: resultados do universo. Brasília; 2000 [acesso em 2/12/2005]. Disponível em: http://www.ibge.gov.br/home/estatistica/populacao/censo2000/ 
Tabela 1. Distribuição de mulheres agredidas e não agredidas segundo variáveis sociodemográficas. João Pessoa, PB, 20042005

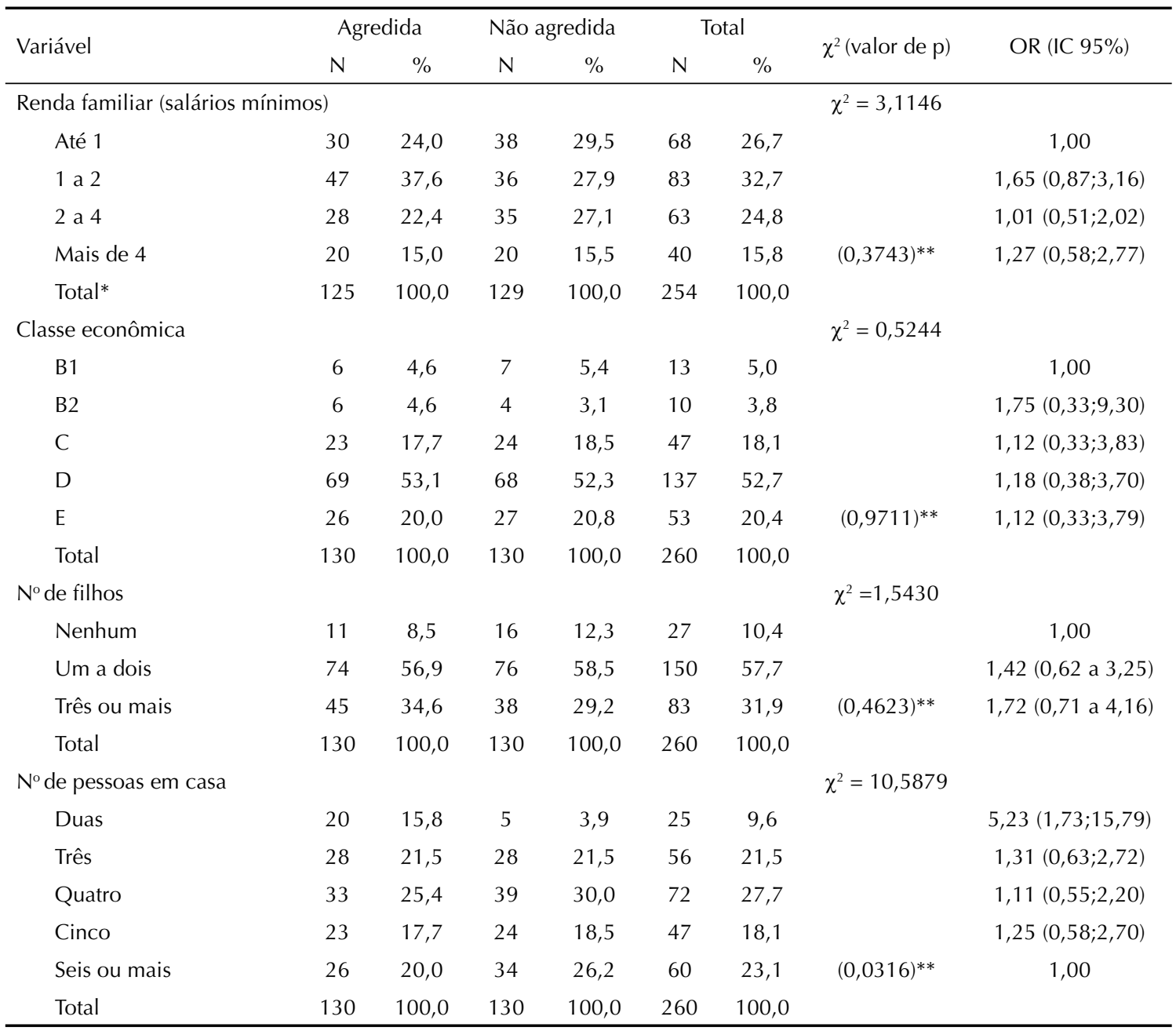

* Para seis pesquisados não se dispunha desta informação

** Teste qui-quadrado de Pearson

Tabela 2. Distribuição das mulheres agredidas e não agredidas segundo uso e freqüencia do consumo de drogas pela família. João Pessoa, PB, 2004-2005.

\begin{tabular}{|c|c|c|c|c|c|c|c|c|}
\hline \multirow{2}{*}{ Variável } & \multicolumn{2}{|c|}{ Agredida } & \multicolumn{2}{|c|}{ Não agredida } & \multicolumn{2}{|c|}{ Total } & \multirow{2}{*}{$\chi^{2}($ Valor de $\mathrm{p})$} & \multirow{2}{*}{ OR (IC 95\%) } \\
\hline & $\mathrm{N}$ & $\%$ & $\mathrm{~N}$ & $\%$ & $\mathrm{~N}$ & $\%$ & & \\
\hline Uso de droga & & & & & & & $\chi^{2}=38,5539$ & \\
\hline Sim & 118 & 90,8 & 74 & 56,9 & 192 & 73,9 & $(<0,0001)^{*}$ & $7,44(3,73 ; 14,80)$ \\
\hline Não & 12 & 9,2 & 56 & 43,1 & 68 & 26,1 & & 1,00 \\
\hline Total & 130 & 100,0 & 130 & 100,0 & 260 & 100,0 & & \\
\hline \multicolumn{3}{|c|}{ Freqüência do consumo de droga } & & & & & $\chi^{2}=70,5558$ & \\
\hline Não usa & 12 & 9,4 & 56 & 43,1 & 68 & 26,4 & $(p<0,0001)^{*}$ & 1,00 \\
\hline Ocasionalmente & 19 & 14,9 & 37 & 28,4 & 56 & 21,8 & & $2,40(1,04 ; 5,51)$ \\
\hline Finais de semana & 48 & 37,7 & 31 & 23,8 & 79 & 30,8 & & $7,23(3,35 ; 15,60)$ \\
\hline Diariamente & 48 & 37,8 & 6 & 4,6 & 54 & 21,0 & & $37,33(13,02 ; 107,01)$ \\
\hline Total & 127 & 100,0 & 130 & 100,0 & 257 & 100,0 & & \\
\hline
\end{tabular}

* Teste qui-quadrado de Pearson

** Para três pesquisados não se dispunha desta informação 
Tabela 3. Distribuição das mulheres agredidas e não agredidas segundo tipo de droga e membro da família usuário. João Pessoa, PB, 2004-2005.

\begin{tabular}{|c|c|c|c|c|c|c|c|c|}
\hline \multirow{2}{*}{ Variável } & \multicolumn{2}{|c|}{ Agredida } & \multirow{2}{*}{\multicolumn{2}{|c|}{$\begin{array}{l}\text { Não agredida } \\
\mathrm{N}\end{array}$}} & \multicolumn{2}{|c|}{ Grupo total } & \multirow{2}{*}{$\chi^{2}($ Valor de $p)$} & \multirow{2}{*}{ OR (IC 95\%) } \\
\hline & $\mathrm{N}$ & $\%$ & & & $\mathrm{~N}$ & $\%$ & & \\
\hline Tipo de droga & & & & & & & $\chi^{2}=44,7187$ & 1,00 \\
\hline Não usa & 12 & 9,2 & 56 & 43,1 & 68 & 26,1 & $(<0,0001)^{* *}$ & $6,51(3,25 ; 13,02)$ \\
\hline Álcool & 99 & 76,2 & 71 & 54,6 & 170 & 65,4 & & $29,56(7,52 ; 116,08)$ \\
\hline Álcool + outra droga* & 19 & 14,6 & 03 & 2,3 & 22 & 8,5 & & \\
\hline Total & 130 & 100,0 & 130 & 100,0 & 260 & 100,0 & & \\
\hline \multicolumn{9}{|l|}{ Membro da família usuário } \\
\hline Ninguém & 12 & 9,2 & 56 & 43,1 & 68 & 26,2 & $(<0,0001)^{* * *}$ & 1,00 \\
\hline $\begin{array}{l}\text { Companheiro e ex- } \\
\text { companheiro }\end{array}$ & 110 & 84,6 & 52 & 40,0 & 162 & 62,4 & & $9,87(4,88 ; 19,99)$ \\
\hline Filhos & 1 & 0,8 & 5 & 3,8 & 6 & 2,3 & & $0,93(0,10 ; 8,73)$ \\
\hline Outros $* * * *$ & 7 & 5,4 & 17 & 13,1 & 24 & 9,2 & & $1,92(0,65 ; 5,65)$ \\
\hline Total & 130 & 100,0 & 130 & 100,0 & 260 & 100,0 & & \\
\hline
\end{tabular}

* Maconha, cocaína, crack e ropinol (flunitrazepan)

** Teste qui-quadrado de Pearson

*** Teste Exato de Fisher

**** Irmãos, pai, primos, cunhados

significativa entre os dois grupos $(\mathrm{p}=0,4129)$. A média de idade do grupo das agredidas foi de 30,14 anos $(\mathrm{DP}=9,60)$ e, no grupo de mulheres não agredidas, 31,14 anos $(\mathrm{DP}=10,06)$.

A média do tempo de estudo foi menos de um ano mais elevada entre as mulheres agredidas $(8,21 ; \mathrm{DP}=4,15)$ do que entre os do grupo das não agredidas $(9,02$; $\mathrm{DP}=4,38)$, também sem diferença significativa entre os dois grupos $(\mathrm{p}=0,1247)$.

A média de renda familiar foi até dois salários mínimos e as classes econômicas de menor poder de consumo (D e E) foram as mais freqüentes.

Na Tabela 1, observa-se que as variáveis renda familiar, classe econômica e número de filhos não apresentaram diferença significativa entre os grupos $(\mathrm{p}=0,3743$, $\chi^{2}=3,11 ; \mathrm{p}=0,9711, \chi^{2}=0,52 ; \mathrm{p}=0,4623, \chi^{2}=1,54$, respectivamente).

Considerando-se o número de pessoas na casa, o percentual de residências com duas pessoas foi mais elevado no grupo das mulheres agredidas $(15,8 \%)$ do que nas não agredidas $(3,9 \%)$; residências com quatro ou mais pessoas foram mais freqüentes no grupo das mulheres não agredidas, sendo estatisticamente diferentes entre os dois grupos $\left(\mathrm{p}=0,0316 ; \chi^{2}=10,59\right)$ (Tabela 1). A chance de exposição à violência foi cinco vezes maior em mulheres que moram apenas com uma pessoa do que com famílias maiores $(\mathrm{OR}=5,23$ para famílias constituídas por duas pessoas). O principal agressor foi o companheiro/esposo $(58,5 \%)$, seguido do ex-companheiro $(31,5 \%)$.
Verifica-se na Tabela 2 que as famílias das mulheres agredidas tinham maior freqüência de uso de drogas $(90,8 \%)$ do que as famílias das mulheres não agredidas $(56,9 \%)$, diferenças significativas estatisticamente $\left(\mathrm{p}=0,0001 ; \chi^{2}=38,55\right)$. As chances de exposição à violência doméstica foi sete vezes maior quando havia consumo de drogas $(\mathrm{OR}=7,44)$.

No grupo das mulheres agredidas, a freqüência diária de uso de drogas foi a mais comum diariamente $(37,8 \%)$, seguida dos que consumiam no final de semana $(37,7 \%)$. No grupo das não agredidas, as freqüências maiores foram para as famílias que não consumiam $(43,1 \%)$, seguido de consumo ocasional $(28,4 \%)\left(p<0,00001 ; \chi^{2}=70,55\right)$ (Tabela 2). Observouse, ainda, que o consumo diário determinou um risco de agressão maior $(\mathrm{OR}=37,33)$ em relação aos que não apresentaram este padrão de consumo, assim como o consumo em todo final de semana $(\mathrm{OR}=7,23)$.

A Tabela 3 mostra que a droga mais consumida pelas famílias foi o álcool entre 76,2\% das agredidas e 54,6\% das não agredidas. Outras substâncias apareceram associadas ao álcool: maconha, cocaína, crack, ropinol (flunitrazepam) em $14,6 \%$ do grupo caso e em 2,3\% do grupo controle $\left(\mathrm{p}<0,0001 ; \chi^{2}=44,71\right)$. Ainda na Tabela 3 , observa-se que quando o álcool foi associado à outra substância como maconha, cocaína, crack, ou ropinol, a chance de ocorrer agressão aumentou em 29 vezes $(\mathrm{OR}=29,56)$, apesar da amplitude do intervalo de confiança $(7,52$ - 116,08). Em consumo exclusivo de álcool, o risco foi seis vezes maior em relação à família que não consumia nenhuma droga $(\mathrm{OR}=6,51)$. 
Tabela 4. Distribuição das mulheres agredidas e não agredidas segundo risco mental, coesão e adaptabilidade familiar. João Pessoa, PB, 2004-2005.

\begin{tabular}{|c|c|c|c|c|c|c|c|c|}
\hline \multirow{2}{*}{ Variável } & \multicolumn{2}{|c|}{ Agredida } & \multicolumn{2}{|c|}{ Não agredida } & \multicolumn{2}{|c|}{ Total } & \multirow{2}{*}{$\chi^{2}$ (Valor de $\left.p\right)$} & \multirow{2}{*}{ OR (IC 95\%) } \\
\hline & $\mathrm{N}$ & $\%$ & $\mathrm{~N}$ & $\%$ & $\mathrm{~N}$ & $\%$ & & \\
\hline Risco mental & & & & & & & $\chi^{2}=12,8541$ & \\
\hline Família balanceada & 23 & 17,7 & 29 & 22,3 & 52 & 20,0 & $(0,0016)^{*}$ & 1,00 \\
\hline Médio risco & 51 & 39,2 & 72 & 55,4 & 123 & 47,3 & & $0,89(0,46 ; 1,72)$ \\
\hline Alto risco & 56 & 43,1 & 29 & 22,3 & 85 & 32,7 & & $2,43(1,20 ; 4,94)$ \\
\hline Total & 130 & 100,0 & 130 & 100,0 & 260 & 100,0 & & \\
\hline Coesão & & & & & & & $\chi^{2}=69,3024$ & \\
\hline Desligada & 92 & 70,8 & 28 & 21,5 & 120 & 46,2 & $(<0,0001)^{*}$ & $16,73(7,72 ; 36,22)$ \\
\hline Separada & 27 & 20,8 & 46 & 35,4 & 73 & 28,1 & & $3,00(1,34 ; 6,66)$ \\
\hline $\begin{array}{l}\text { Conectada/ } \\
\text { Aglutinada }\end{array}$ & 11 & 8,5 & 56 & 43,1 & 67 & 25,8 & & 1,00 \\
\hline Total & 130 & 100,0 & 130 & 100,0 & 260 & 100,0 & & \\
\hline Adaptabilidade & & & & & & & $\chi^{2}=6,4483$ & \\
\hline Rígida & 62 & 47,7 & 61 & 46,9 & 123 & 47,3 & $(0,0917)^{*}$ & $1,92(0,79 ; 4,64)$ \\
\hline Estruturada & 43 & 33,1 & 29 & 22,3 & 72 & 27,7 & & $2,80(1,10 ; 7,14)$ \\
\hline Flexível & 16 & 12,3 & 23 & 17,7 & 39 & 15,0 & & $1,31(0,47 ; 3,68)$ \\
\hline Caótica & 9 & 6,9 & 17 & 13,1 & 26 & 10,0 & & 1,00 \\
\hline Total & 130 & 100,0 & 130 & 100,0 & 260 & 100,0 & & \\
\hline
\end{tabular}

* Teste qui-quadrado de Pearson

O companheiro e o ex-companheiro foram os mais citados como usuários de drogas em cada grupo (84,6\% agredidas e 40,0\% não agredidas), aumentando em nove vezes o risco de ocorrer violência $(\mathrm{OR}=9,87)$ (Tabela 3).

Na Tabela 4 são apresentados risco mental, coesão e adaptabilidade para os casos e controles. No grupo dos controles, o maior percentual $(55,4 \%)$ correspondeu às pesquisadas que tinham risco mental médio, enquanto que, no grupo das mulheres agredidas, o maior percentual correspondeu às que tinham alto risco $(43,1 \%)\left(\mathrm{p}=0,0016 ; \chi^{2}=12,85\right)$. Os dados para o risco mental familiar mostram que a chance de exposição à violência foi duas vezes maior em famílias de alto risco $(\mathrm{OR}=2,43)$.

Em relação à coesão familiar, no grupo das mulheres agredidas, $70,8 \%$ das pesquisadas tinha coesão desligada; no grupo controle, o maior percentual correspondeu à coesão conectada $(43,1 \%)\left(p<0,0001 ; \chi^{2}=69,30\right)$. A chance de casos de violência doméstica foi dezesseis vezes mais alta em famílias de coesão desligada $(\mathrm{OR}=16,73)$.

Sobre a adaptabilidade, o maior percentual no grupo total correspondeu à categoria rígida $(47,3 \%)$, sem diferença significativa $\left(p=0,0917 ; \chi^{2}=6,45\right)$ entre os dois grupos.

A Tabela 5 mostra os resultados da regressão logística e os valores do OR. O uso de droga pela família em relação aos que não utilizavam e a categoria alto risco mental em relação à categoria família balanceada apresentaram diferenças significativas. Os OR mostraram relação mais forte entre o uso de drogas $(\mathrm{OR}=7,74)$ e agressão física doméstica do que entre esta e risco mental alto $(\mathrm{OR}=3,14)$. A probabilidade de a mulher ser agredida aumentou quando os membros das famílias eram usuários de droga $(\mathrm{OR}=5,81)$, com coesão desligada ou separada $(\mathrm{OR}=22,03)$ quando comparadas com as famílias conectadas/aglutinadas.

\section{DISCUSSÃO}

O presente trabalho mostra que a maioria das mulheres que sofreram violência era jovem, em contraste com autores ${ }^{7,15,21-23}$ que relataram faixas de idade de até 44 anos. Isso mostra que, provavelmente, a agressão às mulheres no âmbito familiar está relacionada à vida sexual ativa, pois estas mulheres eram mais jovens do que aquelas estudadas por outros autores.

As mulheres do presente artigo apresentaram média de oito anos de estudo, semelhante a outros trabalhos ${ }^{9,16}$ que encontraram em torno de $60 \%$ das mulheres com ensino fundamental incompleto. Adeodato ${ }^{1}$ et al (2005) afirmam que o esclarecimento da mulher leva a menor tolerância à violência. Quanto mais a mulher se qualifica, mais chance tem de encontrar trabalho remunerado, melhorando assim a auto-estima e independência.

Embora a literatura ${ }^{2}$ relate que a pobreza e a falta de padrões morais conduzam à violência, esta pode estar 
Tabela 5. Regressão logística da ocorrência de violência familiar segundo uso de drogas por membros familiares, risco mental, coesão e adaptabilidade familiar. João Pessoa, PB, 2004-2005.

\begin{tabular}{|c|c|c|c|}
\hline \multirow{2}{*}{ Variável } & OR (IC 95\%) & OR (IC 95\%) & \multirow{2}{*}{ Valor de $p$} \\
\hline & Bruta & Ajustada & \\
\hline \multicolumn{4}{|l|}{ Uso de droga } \\
\hline Sim & $7,44(3,73 ; 14,80)$ & $7,74(3,46 ; 17,31)$ & 0,0001 \\
\hline Não & 1,00 & 1,00 & \\
\hline \multicolumn{4}{|l|}{ Risco mental } \\
\hline Família balanceada & 1,00 & 1,00 & \\
\hline Médio risco & $0,89(0,46 ; 1,72)$ & $1,02(0,45 ; 2,32)$ & 0,9615 \\
\hline Alto risco & $2,43(1,20 ; 4,94)$ & $3,14(1,29 ; 7,64)$ & 0,0119 \\
\hline \multicolumn{4}{|l|}{ Coesão } \\
\hline Desligada & $16,73(7,72 ; 36,22)$ & $22,03(6,68 ; 72,62)$ & $<0,0001$ \\
\hline Separada & $3,00(1,34 ; 6,66)$ & $3,17(1,01 ; 9,92)$ & 0,0474 \\
\hline Conectada/Aglutinada & 1,00 & 1,00 & \\
\hline \multicolumn{4}{|l|}{ Adaptabilidade } \\
\hline Rígida & $1,92(0,79 ; 4,64)$ & $1,17(0,22 ; 6,09)$ & 0,8512 \\
\hline Estruturada & $2,80(1,10 ; 7,14)$ & $2,69(0,61 ; 11,78)$ & 0,1894 \\
\hline Flexível & $1,31(0,47 ; 3,68)$ & $1,64(0,49 ; 6,68)$ & 0,4903 \\
\hline Caótica & 1,00 & 1,00 & \\
\hline
\end{tabular}

inserida em classes mais abastadas. Adeodato ${ }^{1}$ et al (2005) relatam que mulheres de maior poder aquisitivo dispõem de recursos políticos e econômicos para ocultar a violência doméstica, surgindo, então, a sub-representação nos dados de violência denunciada.

O número de filhos por mulher no presente estudo (um a dois) é semelhante ao trabalho de Galvão \& Andrade 9 (2004), corroborando dados do Instituto Brasileiro de Geografia e Estatística* (IBGE 2005) que indicam a queda da fecundidade da mulher brasileira. A inserção da mulher no mercado de trabalho e a mudança dos conceitos da estrutura familiar vêm contribuindo para esse fato. Ainda nesse aspecto, deve-se associar o número de filhos ao número de pessoas que residem na mesma casa. De acordo com os resultados do presente estudo, as famílias constituídas por apenas duas pessoas residindo na mesma casa tiveram cinco vezes mais chances de a mulher ser vítima de violência, quando comparado às famílias constituídas por mais pessoas. Esse resultado levanta a hipótese de que as famílias constituídas por marido, mulher, filhos do casal, filhos de casamentos anteriores, sogra, sogro e cunhados, podem inibir agressões físicas.

$\mathrm{Na}$ maioria dos estudos, o agressor mais freqüente da mulher foi o companheiro/esposo ou ex-companheiro, com percentagens que variam de $73,0 \%$ a $80,0 \% \cdot{ }^{4,7}$ No presente estudo, as notificações contra os companheiros/ex-companheiros foi maior $(90 \%)$ do que os estudos citados.

Autores como Giffin ${ }^{11}$ (2002) relacionam as relações violentas masculinas com o desemprego, o que resulta em desestruturação da identidade masculina, refletindo violentamente em suas parceiras. Esse autor citou que o poder do macho, na sociedade contemporânea foi deslocado da rua para a casa e depois para o corpo.

A maioria das famílias das mulheres que participaram do presente estudo consumia drogas, sendo o álcool a substância mais utilizada e diariamente consumida. Por outro lado, a literatura ${ }^{11}$ relata que o risco da associação do álcool com a agressão física não ocorre apenas com os bebedores abusivos e regulares, mas também entre bebedores moderados ou eventuais. Adeodato et $\mathrm{al}^{1}$ (2005) identificaram que $70 \%$ dos parceiros ingeriram álcool e, em 11\%, drogas ilícitas. Estes autores salientaram a correlação direta entre consumo de álcool pelo agressor e agressão aos filhos. Njaine \& Minayo $^{17}$ (2004) citam que o consumo de álcool começa cada vez mais cedo e adolescentes copiam os modelos dos adultos na freqüência do consumo de álcool e embriaguez.

O consumo de álcool pelos agressores das mulheres que sofrem violência doméstica aparece em outros estudos, e Meneguel et al ${ }^{16}(2000)$ ainda observaram que $37,2 \%$

* Instituto Brasileiro de Geografia e Estatística. Censo demográfico 2000: Características da população e dos domicílios: resultados do universo. Brasília; 2000 [acesso em 2/12/2005]. Disponível em: http://www.ibge.gov.br/home/estatistica/populacao/censo2000/ 
usavam maconha e 32,7\% cocaína. O álcool parece ser a droga mais nociva ao funcionamento familiar, pois, por ser aceito socialmente, há largo consumo principalmente pelos homens. Mesmo considerando um possível exagero por parte das depoentes, traumatizadas com as agressões, certamente o consumo de álcool nas famílias de risco é mais elevado do que no restante da população, vulnerabilizando ainda mais essas famílias. ${ }^{16}$ Baixas escolaridade e renda e o stress emocional para o homem são perpetuadores do alto consumo de álcool e da violência em família. ${ }^{5}$

Em relação ao funcionamento familiar, estudo de Arcos et $\mathrm{al}^{2}$ (1999) mostra maior disfunção e risco para as mulheres com experiências de agressão doméstica em confronto ao grupo sem violência. Os itens do questionário - menor apoio familiar ao desenvolvimento pessoal da mulher agredida e menor interação para compartilhar tempo livre, espaço e dinheiro - mostraram diferenças estatisticamente significativas entre os grupos. A percepção da mulher sobre sua relação com o companheiro mostrou diferenças significativas entre os dois grupos para os itens do questionário: maior número de discussões e menor compreensão do homem para com a mulher. $\mathrm{O}$ companheiro das mulheres que sofreram agressão era sete vezes menos compreensivo do que no grupo das não agredidas.

As famílias com alto risco mental têm duas vezes mais chances de apresentar violência na família, conforme o presente estudo. A análise dos dados de Adeodato $^{1}$ et al (2005) sugere que a violência doméstica está associada à percepção negativa da saúde mental da mulher, das quais 78\% apresentavam ansiedade e insônia, 65\% sintomas somáticos, $40 \%$ depressão grave e $26 \%$ disfunção social.
Em relação à coesão familiar, os dois grupos se comportaram de forma diferente. A família de coesão desligada possuía 16 vezes mais chances de expor seus membros à violência. Nota-se pelas respostas, que nas famílias onde há a agressão física, os membros não passam o tempo livre juntos, nem compartilham atividades em família. Geralmente, as mulheres agredidas se sentiam mais próximas a alguém estranho do que aos familiares. Quanto à adaptabilidade familiar no presente estudo, a liderança da família estava relacionada ao provedor da casa, geralmente o homem, com pouca alternância do líder. Raramente, havia mudança de regras em casa e de rodízio nas tarefas domésticas. Os filhos possuíam pouca ou nenhuma decisão em casa e pouco expressaram suas opiniões ou sugeriram soluções para os problemas da família. Esse comportamento familiar rígido foi observado nos dois grupos de mulheres, sugerindo que o padrão cultural brasileiro, principalmente o nordestino, promove este tipo de família com pouca flexibilidade para adaptação aos desafios do dia-a-dia.

Os resultados encontrados também podem levantar hipóteses de causalidade reversa: a coesão desligada levou as famílias à agressão ou a violência física levou a família a possuir coesão desligada? $\mathrm{O}$ consumo de drogas entre os membros da família aumenta a coesão desligada e violência doméstica ou a presença de coesão desligada e de agressão física também aumenta o consumo de substâncias lícitas e ilícitas? Todos esses fatores estão interligados e, em sua presença, o relacionamento familiar perde o equilíbrio.

É necessário um esforço da sociedade para discutir a família brasileira no tocante à sua formação histórica e ao processo de mudança que os novos tempos impuseram à mulher. 


\section{REFERÊNCIAS}

1. Adeodato VG, Carvalho RR, Siqueira VR, Souza FGM. Qualidade de vida e depressão em mulheres vítimas de seus parceiros. Rev Saude Publica. 2005;39(1):10813.

2. Arcos E, Molina I, Repossi A, Uarac M, Ritter P, Arias L. Violencia doméstica y sexualidad. Rev Med Chil. 1999;127(11):1329-38.

3. Bucher JSN. A mulher e o trabalho. Rev Promoc Saude. 2002;3(6):14-6.

4. Camargo CNMF. Agressor ou vítima: a falta básica e as duas faces da mesma moeda. In: Ferrari DCA, Vecina TCC, organizadores. O fim do silêncio na violência familiar. São Paulo: Agora; 2002. p.131-40.

5. Chase KA, O'Farrel TJ, Murphy CM, Fals-Sterwart W, Murphy $M$. Factors associated with partner violence among female alcoholic patients and their male partners. J Stud Alcohol. 2003;64(1):137-49.

6. Chinoy E. Família, Parentesco e Matrimônio. In: Sociedade: uma Introdução à Sociologia. São Paulo: Cultrix; 1999. p. 200-43.

7. Deslantes SF, Gomes R, Silva CM. Caracterização dos casos de violência doméstica contra a mulher atendidos em dois hospitais públicos do Rio de Janeiro. Cad Saude Publica. 2000;16(1):129-37.

8. Falceto OG, Busnello ED, Bozzetti MC. Validação de escalas diagnósticas do funcionamento familiar para utilização em serviços de atenção primária à saúde. Rev Panam Salud Publica. 2000;7(4):255-263.

9. Galvão EF, Andrade SM. Violência contra a mulher: análise de casos atendidos em serviço de atenção à mulher em município do sul do Brasil. Saude Soc.2004;13(2):89-99.

10. Gianini RJ, Litvoc J, Eluf Neto J. Agressão física e classe social. Rev Saude Publica. 1999;33(2):180-6.

11. Giffin K. Pobreza, desigualdade e equidade em saúde: considerações a partir de uma perspectiva de gênero transversal. Cad Saude Publica. 2002;18 Supl:103-12

12. Kishor $\mathrm{S}$. The heavy burden of a silent scourge: domestic violence. Rev Panam Salud Publica. 2005;17(2):77-8.
13. Leão EM, Marinho LFB. Saúde das mulheres no Brasil: subsídios para as políticas públicas de saúde. Rev Promoc Saude. 2002;3(6):31-6.

14. Mattar FN. Análise crítica dos estudos de estratificação sócio-econômica de ABA-Abipeme. Rev Adm 1995;30(1):57-74.

15. Hijar-Medina M, Flores-Regata L, Valdez-Santiago R, Blanco J. Atención médica de lesiones intencionales provocadas por la violencia familiar. Salud Publica Mex. 2003;45(4):252-8.

16. Meneguel SN, Camargo M, Fasolo LR, Mattiello DA, Silva RC, Santos TC, et al. Mulheres cuidando de mulheres: um estudo sobre a Casa de Apoio Viva Maria, Porto Alegre, Rio Grande do Sul, Brasil. Cad Saude Publica. 2000;16(3):747-57.

17. Njaine K, Minayo MCS. A violência na mídia como tema da área da saúde pública: revisão da literatura. Cienc Saude Coletiva. 2004;9(1):201-11.

18. Olson DH, Sprenkle D, Russel C. Circumplex model: systemic assessment and treatment of families. New York: The Harworth Press; 1989.

19. Pastore J. A mulher dos anos 2000. Rev Promoc Saude. 2002;3(6):8-10.

20. Penna LHG, Santos NC, Souza ER. A produção Científica sobre violência doméstica na área da Saúde Pública. Rev Enferm UFRJ. 2004;12(2):192-8.

21. Rabello PM, Félix SSS, Leite ICC, Alves JS, Alves NSS, Silva RM. Importância do Odontolegista no exame de corpo de delito, 460 casos de mulheres agredidas, DML, João Pessoa-PB. Rev Saude Etica Just. 1998;3(1/2):25-32.

22. Valdez-Rojas JC, Salasar-Lima A, Hernández-Morejon E, Dmínguez-Sancher M, Torre-Dianez R, BarbosaRodríguez D. Violência Intrafamiliar. Enfoque de gênero. Rev Cubana Med Gen Integr. 2002;18(4):24850 .

23. Schraiber LB, D'Oliveira AF. Violência contra a mulher: pesquisa e intervenção. Rev Promoc Saude. 2002;3(6):80-3.

Artigo baseado na tese de doutorado de PM Rabello, apresentada à Faculdade de Odontologia da Universidade de Pernambuco, em 2006. 